\title{
PSICONEUROCIENCIA Y ARQUETIPOS - CONSTRUYENDO UN DiÁLOGO ENTRE PSICOLOGÍA ANALÍTICA Y NEUROCIENCIA
}

\author{
Mario E. Saiz y Pilar Amézaga ${ }^{1}$ \\ Facultad de Psicología de la Universidad Católica del Uruguaye \\ Sociedad Uruguaya de Psicologia Analítica
}

El sostenido desarrollo de las neurociencias en el estudio del cerebro y la conducta humana, junto al desarrollo de puentes epistemológicos entre las psicociencias, especialmente referidos al estudio de la mente y al alma humana, ha comenzado a generar una complementariedad $e$ integración del conocimiento desde diferentes disciplinas científicas, buscando la formulación de una teoría unificada cerebro-mente. En el contexto de esta generación de conocimiento, ha surgido la propuesta de los autores de un espacio transdisciplinario de estudio de las relaciones entre la mente y el cerebro, entre neurociencias y psicociencias, que denominan Psiconeurociencia. Desde esta perspectiva los autores plantean una re-visión de la noción de arquetipo formulada por la Psicología Analítica a la luz de los aportes de la neurociencia y de la psicología cognitiva, para describir a modo de ejemplo de este reformulación, los patrones de organización que interactúan en los trastornos depresivos.

Palabras claves: Neurociencias. Neuropsicologia. Psicologia junguiana.

$\mathrm{E}$ comienzo de este siglo se ha caracterizado por un desarrollo sostenido de las diferentes disciplinas científicas que trabajan en forma complementaria e integrada para generar conocimientos en el campo de las

1 Av. 8 de Octubre 2738 - 11600 - Montevideo - Uruguay - Tel: 59824872717 * 375 - Fax: 598248762 04. E-mail: msaiz@ucu.edu.uy 
neurociencias. Esta nueva realidad contextuada por el desarrollo de la investigación en el campo de las neurociencias, la imagenología cerebral, la genómica humana, y la neurobiología molecular, nos están planteando, por un lado, la necesidad de rever nuestras cartografías, y especialmente nuestras fronteras entre la biología y la psicología, buscando la construcción de una teoría unificada cerebro-mente. A su vez, por otro lado, estos desarrollos están promoviendo el encuentro interdisciplinario entre las ciencias, y posibilitando el surgimiento de los primeros pasos de un diálogo entre las psicociencias en el camino hacia la construcción de una psicología y una psicoterapia integrativa, con especial énfasis en las relaciones entre neurociencias, psicología cognitiva y Psicología Analítica.

Desde la neurobiología, Eric R. Kandel, Premio Nóbel de Medicina, nos propone que el próximo paso en Neurociencia será: "la unificación del estudio de la conducta, la ciencia de la mente, y la neurociencia, la ciencia del cerebro. Este último paso nos permitirá lograr un enfoque científico unificado del estudio de la conducta” (Kandel, Schwartz, \& Jessel, 2001, p. 5).

Desde la Psicología Analítica, Carl G. Jung nos plantea que

indudablemente la idea del unus mundus se basa en el supuesto de que la multiplicidad del mundo empírico se apoya en una unidad subyacente, no en la coexistencia o combinación de dos o más mundos fundamentalmente diferentes (...). La existencia de innegables conexiones causales entre la psique y el cuerpo confirman la naturaleza unitaria subyacente... (Jung, 1944/1970, pp. 537-538)

El encuentro de estas dos propuestas epistemológicas promueve en nosotros una revisión de nuestras cartografías sobre la relación cerebromente a través de un camino de interdisciplinariedad, surgido desde las investigaciones realizadas en el campo de las neurociencias (Neurociencia Cognitiva), y el campo de las psicociencias (Psicología Analítica). En el marco de la propuesta de Jung de que "la separación de la psicología de los postulados básicos de la biología es puramente artificial, ya que la psique humana existe en una unión indisoluble con el cuerpo” (Jung, 1937/1968, p. 114), es que estamos desarrollando un dominio propio llamado 


\section{Psiconeurociencia y Arquetipos}

Psiconeurociencia ${ }^{2}$ con el propósito de contribuir al diseño de una cartografía unificada de la relación cerebro-mente.

Nuestro objetivo es investigar a partir de los patrones descriptos por la neurociencia, la Psicología Analítica y la Psicología Cognitiva, la existencia de patrones comunes de organización subyacentes, que están incidiendo en la forma en que se organiza, estructura y procesa la personalidad y el mundo de nuestros pacientes. Para ello partiremos de los estudios realizados en torno al concepto de arquetipo por Stevens (2003), Hogenson (2003), y Knox (2003), y los estudios neurobiológicos y neuroepistemológicos de Maturana (1996) y Varela (1988) para realizar, en el dominio de la Psiconeurociencia, una re-visión de la noción de arquetipo que nos permita definirlo como un patrón de organización.

El concepto de arquetipo, formulado por Jung, es el concepto más importante de la Psicología Analítica ya que nos permite trascender el sentido restringido del símbolo como signo, para incorporarlo como una función estructurante a la totalidad del Self personal, cultural y planetario (Byington, 2003). Jung describió los arquetipos como las matrices del inconsciente colectivo de la especie humana.

Los arquetipos son, por definición, factores y motivos que ordenan los elementos psíquicos en ciertas imágenes, caracterizadas como arquetípicas, pero de tal forma que sólo se pueden reconocer por los efectos que producen. Ellos (...) presumiblemente forman las dominantes estructurales de la psique en general. (Jung, 1942/1969, p. 149)

2 La propuesta de acuñar el término Psiconeurociencia fue presentado en el I Jornada Latinoamericana de Neurociencia Cognitiva (AAIN), (Saiz, 1999), en XVI Congreso Argentino de Psiquiatría (Saiz, 2000), en el XV Congreso Internacional de Psicología Analítica (Saiz,2001), así como en el III Congreso Latinoamericano de Psicología Junguiana (Saiz, 2003), y en el XVI International Congress for Analytical Psychology, (Saiz \& Amezaga, 2004), para referirnos al desarrollo de un dominio transdisciplinario donde se estudia la trama unificada de las relaciones y conexiones que establecen el puente entre el campo de la neurociencias y de las psicociencias. 
Lo arquetípico pertenece a un nivel de experiencia que es diferente del nivel explicativo de su definición. Como primer paso, basándonos en la reconstrucción de nuestras cartografías, reconsideraremos su definición desde el nivel explicativo. La propuesta de Jung de considerar los arquetipos "como factores y motivos que ordenan los elementos psíquicos...", nos permite postular una re-definición del arquetipo como un patrón de organización. Destacamos precisamente su carácter ordenador de los elementos psíquicos, haciendo extensiva esta capacidad ordenadora, propia de cada patrón específico, a toda la psique. Partiendo del pensamiento de Jung, nuestra propuesta se va ir consolidando e enriqueciendo con los aportes de la neuroepistemología de Maturana y Varela (1987) quienes establecen una distinción clave entre organización y estructura. También integramos los aportes analíticos de Stevens (2003), y de la epistemología simbólica de Byington (1996, 2003), cuando plantean una ampliación de la noción de arquetipo para incluir las manifestaciones conscientes además de las inconscientes.

\section{Arquetipo: patrón de organización}

Por patrón de organización de un sistema vivo entendemos el conjunto de las relaciones entre sus componentes que caracteriza al sistema como perteneciente a una clase determinada, sea una ameba, un narciso o un cerebro humano. La descripción de dicha organización es una descripción abstracta de las relaciones y no de sus componentes. Constituye lo que Maturana (1996) ha definido como patrón de organización de un sistema.

La estructura de un sistema refiere a los componentes y sus relaciones, en otros términos, la estructura es la corporeización del patrón de organización. En definitiva, el patrón de organización de un sistema es independiente de las propiedades de sus componentes, de modo que toda organización puede ser corporeizada de distintas maneras y con diferentes componentes. En otras palabras, para tener información sobre las propiedades de los componentes y sus interacciones, no alcanza con la descripción abstracta del patrón de organización, sino que requiere una 
descripción de la estructura del sistema según corresponda, en un lenguaje físico, químico, biológico o simbólico.

En este marco epistemológico, Maturana y Varela (1980) definen el patrón de organización general de los sistemas vivos como autopoiesis, haciendo referencia a la autonomía de los sistemas vivos para autoorganizarse, es decir de "crearse a sí mismo", cualquiera sea la naturaleza de sus componentes. A su vez, todo patrón de organización es un patrón de red, donde la función de cada componente es ayudar a producir y transformar a los otros componentes, manteniendo al mismo tiempo la circularidad global de la red. El patrón de organización sólo puede ser reconocido si está corporeizado en una estructura, siendo éste un proceso continuo en los organismos vivos. Para Maturana (1996), esta relación entre patrón de organización y estructura es aplicable al cerebro humano, el cual no es solamente auto-organizador sino también auto-referente. Por tanto, toda percepción no puede ser considerada como una representación de una realidad externa, sino que debe ser entendida como la creación continua de nuevas relaciones en el interior de las redes neuronales. La percepción, y en términos generales, toda cognición, no representa una realidad externa, sino una específica que es el resultado de los procesos de organización circular propios del sistema nervioso. Estos autores postulan que los "sistemas vivos son sistemas cognitivos y el proceso de vivir es un proceso de cognición. Esta afirmación es válida para todos los organismos, tengan o no sistema nervioso" (Maturana \& Varela, 1987, p. 174). Por tanto, podemos decir, que el cerebro es una de las estructuras que corporeiza el patrón de organización autopoiética que define la organización sistémica de los seres vivos. Así el cerebro es una estructura cognitiva, mientras que la mente es el proceso de cognición que se identifica con el proceso mismo de la vida.

Durante mucho tiempo, desde la neurobiología hasta la neuroepistemología, hemos estado realizando un importante esfuerzo por conectar lo se ha considerado como dos categorías diferentes: cerebro y mente. Luego, hemos abandonado esta empresa por no haber encontrado respuestas consistentes y hemos pasado a explorar otras opciones, las cuales nunca se han consolidado por permanecer subyacente, en nuestro modo de 
pensar, esa incomprensión del dualismo cartesiano, que torna el pensamiento unilateral y fragmentario. Esta nueva cartografía que estamos esbozando parte de la propuesta de Jung de que psique y materia son "dos aspectos diferentes de una misma cosa” (Jung, 1954/1968, p. 215). Cerebro y mente no pueden ser pensados como dos categorías separadas ya que expresan dos dimensiones diferentes del mismo fenómeno de la vida, y por tanto, de la dimensión de lo humano, donde el fenómeno de la mente se halla inseparablemente vinculado al fenómeno de la vida.

Con la hipótesis del arquetipo Jung propone un principio responsable de la articulación entre todos los procesos que gobiernan los factores biológicos y psíquicos de la vida; y todo su abordaje demuestra que pueden ser estudiados de tal forma que no se destruya nuestra toma de conciencia del misterio de la vida. (Stevens, Hogenson, \& Ramos, 2003, p. 42)

En el contexto de esta epistemología de patrones, estructuras y procesos, característico del sistema de los seres vivos y en consecuencia, del sistema cerebro-mente, es que proponemos nuestra re-visión de lo arquetípico, como sistema y como patrón de organización.

\section{Sistema arquetípico}

Desde la publicación de Bertalanffy (1975) Perspectivas en la Teoría General de Sistemas, ha surgido un nuevo paradigma epistemológico donde es necesario investigar el organismo como un todo, ya que cualquier sistema no puede ser descrito como una simple suma de partes investigadas aisladamente. La noción de sistema, como sistema dinámico, implica un patrón de organización que determina las interrelaciones entre las partes desde donde emergen los procesos. En esa misma dirección Bateson desarrolló una nueva concepción de la mente al definir el "proceso mental como un fenómeno sistémico característico de los organismos vivos” (Bateson,1991, p. 515).

El arquetipo en tanto patrón de organización se define por la configuración de las relaciones que se establecen entre sus componentes que determinan las características esenciales del sistema que organiza. El sistema 
que cada patrón organiza convenimos en denominarlo sistema arquetípico, diferenciándolo así del arquetipo como patrón organizador y ordenador del propio sistema.

A su vez, la estructura del sistema hace referencia a los componentes y las relaciones entre ellos, podemos decir, que es la corporeización del patrón de organización arquetípico. Los genes de inducción temprana y catalizadores de algoritmos, junto a la propia actividad neuronal, generan las rutas de conexión sináptica del aprendizaje temprano y de la memoria implícita, que posibilitarán la emergencia de esquemas-imágenes, de esquemas cognitivos, de modelos internos de trabajo, y de patrones simbólicos o del significado personal. Por otro lado, podemos reconocer también entre esas formas de corporeización del patrón, la relación entre los modelos internos de trabajo y la estructura de los complejos descrita por Jung, con sus componentes de pensamientos, imágenes, vivencias, percepciones y comportamientos, los cuales se relacionan y ordenan de acuerdo al patrón de organización arquetípico de referencia.

Por tanto, la trama de lo arquetípico como sistema, se construye en la recursividad de lo genético y lo ambiental, donde el patrón de organización está siempre corporeizado en una estructura, y donde el vínculo entre patrón y estructura, resulta posible a través del proceso de continua corporeización que mantiene activo el patrón de organización del sistema. Esta noción de recursividad entre lo genético y lo ambiental tiene en el campo de la Psicología Analítica sus antecedentes en la noción de arquetipo evolutivo propuesto por Neumann (1954) para describir la formación de la conciencia colectiva y más recientemente, y con mayor énfasis, en la epistemología simbólica de Byington:

La noción de arquetipo, como la de gen, no puede ser pensada fuera del concepto sistémico que incluye múltiples sistemas de retroalimentación (multiple biofeedback system). Cuando unimos el concepto de gen y el de arquetipo al principio de múltiple retroalimentación, vemos que su potencial abstracto, atemporal, y universal se inserta, se amolda y es bastante afectado por el contexto histórico del aquí y ahora. (Byington, 2003, pp. 129-130) 
Por ejemplo, en nuestra perspectiva de la psiconeurociencia, la consideración del Arquetipo de la Gran Madre nos remite a un sistema arquetípico matriarcal, que se auto-organiza de acuerdo a un patrón de organización específico de contención, apego, y cuidado (Gran Madre). Este patrón a su vez se corporeiza en una estructura (complejos) que se construye en base a relaciones e interacciones entre sus componentes (imágenes, emociones, pensamientos, recuerdos, comportamientos). El continuo cambio estructural entre sus componentes, el continuo fluir de las cogniciones y la información requiere de un conjunto de procesos simbólicos definidos como "una experiencia en imágenes y de imágenes” (Jung, 1959/1968, p. 38). En otras palabras, podemos decir que en el vínculo entre patrón y estructura reside el proceso simbólico, entendido éste como la actividad de elaboración simbólica (Byington, 2003, p. 69) que se ocupa de mantener la corporeización psíquica o psiquización del patrón de organización de este sistema arquetípico matriarcal como una totalidad. En nuestro ejemplo, el patrón definido por la contención, el apego y el cuidado es el que organiza el sistema arquetípico matriarcal, al configurar las relaciones entre sus diferentes componentes, y especialmente, entre los símbolos como funciones estructurantes, posibilitando así el desarrollo de toda la dinámica matriarcal que caracteriza a éste sistema.

\section{Emergencia y Génesis}

El comportamiento es una propiedad emergente de un patrón de organización de una red neuronal. Una propiedad emergente es aquella que resulta de la interacción de procesos o agentes locales, es una propiedad que no existe antes de que tales procesos locales interactúen, es precisamente a partir de esta interacción que ella emerge como una nueva propiedad. (Varela, 1988). Así como lo que hace que una célula esté viva no son las moléculas que la componen sino el patrón con el que esas moléculas se ensamblan, lo que hace que un grupo de neuronas ejecute un comportamiento no son las neuronas propiamente como componentes 
sensorio-motores, sino que es el patrón de organización de las conexiones lo que les confiere esa nueva propiedad (Varela \& Haywald, 1997).

Las relaciones estructurales, en el seno de esa red interneuronal que es el cerebro, presenta un nivel de corporeización biológico que abarca desde los algoritmos determinados genéticamente, hasta las redes neuronales implicadas en los procesos neurofisiológicos de re-conexión sináptica que mantienen, dada la plasticidad del sistema nervioso, la permanente interacción recursiva de lo genético y lo ambiental. Esta actividad de interacción entre las estructuras neurales posibilita, a su vez, la emergencia de un nivel de corporeización psíquica o psiquización del patrón de organización de referencia, que abarca desde los procesos psicológicos del aprendizaje temprano y de la memoria implícita, hasta los procesos de abstracción y simbolización propios al ser humano portador de un lenguaje. Podríamos decir, que el patrón de organización determina la configuración de las relaciones entre las diferentes partes constitutivas de la red interneuronal en su acoplamiento estructural con el medio, posibilitando procesos neurales que interactúan entre ellos para generar la emergencia de los procesos psíquicos. Esta afirmación está en la dirección de lo propuesto por Jung, cuando considera que la psique es un logro biológico, y de Stevens, cuando plantea que "la psique en sí misma es un fenómeno biológico con una increíble historia evolutiva muy prolongada” (Stevens et al., 2003, p. 370).

El estudio de cómo se va configurando dinámicamente un sistema arquetípico, requiere de un diálogo de complementariedad e integración en el dominio de la Psiconeurociencia, entre la genética de la conducta y la psicología cognitiva, entre la neurobiología del desarrollo y la psicología simbólico-arquetípica, que nos permita una reformulación del planteo clásico y excluyente entre lo innato y lo emergente respecto del arquetipo. Nuestra consideración sobre la génesis de la organización del sistema arquetípico, es que éste emerge de las interacciones entre patrones de organización, estructuras y procesos. Esta propuesta nos permite plantear un nuevo paradigma epistemológico que da cuenta de las dos visiones diferentes que un mismo observador puede tener sobre lo arquetípico: la que 
define el arquetipo en sí (filogenéticamente), y la que describe las manifestaciones de ese arquetipo (ontogenéticamente).

Se trata de describir cómo se van gatillando los procesos de acoplamiento estructural entre el organismo y el medio, entre lo genético y el aprendizaje temprano, para construir esa organización dinámica y específica que caracteriza a cada sistema arquetípico. El arquetipo en tanto patrón de organización se podría decir que cumple con el principio de autopoiesis propuesto por los neurocientíficos contemporáneos, donde una serie de cambios y redefiniciones a nivel de estructuras y procesos autogeneran la emergencia de los símbolos y de toda la riqueza del mundo psíquico, manteniendo siempre ciertas características estables que lo definen como tal.

Retomando lo propuesto por Jung y, a la luz de las investigaciones actuales, podemos decir que lo que se hereda no son conceptos ni imágenes sino mecanismos automáticos muy básicos que vienen determinados genéticamente, y que luego, en la recursividad entre el organismo y el medio como un todo, posibilitan la emergencia de estos patrones de organización denominados arquetipos. Hablamos de propiedades emergentes para dejar claro que no nos referimos, en este nivel explicativo de definiciones, a propiedades latentes.

Las relaciones entre los componentes estructurales, en tanto corporeización evolutiva de los patrones de organización, alcanzan cada vez mayores grados de complejidad al organizarse en redes para configurar los sistemas arquetípicos. Ellos son una emergencia recursiva entre la información del genoma y la información del ambiente, entre lo filogenético y lo ontogenético. En definitiva, los arquetipos en tanto patrones de organización, son patrones emergentes del desarrollo auto-organizador del cerebro y la psique humana. Son patrones que configuran las relaciones entre las estructuras cerebrales posibilitando la emergencia de una configuración psíquica que define al propio patrón arquetípico. 
Genes, imágenes-esquemas, y modelos representacionales

A modo de ejemplo, consideremos lo que la evidencia científica actual nos muestra sobre la génesis y dinámica de estos procesos que configuran nuestros sistemas arquetípicos. Estos procesos se desencadenan a partir de la acción catalizadora de los genes que disparan la activación de unos pocos patrones automáticos de comportamiento (algoritmos) que dan lugar a las imágenes-esquemas (Mandler, 1992). Cada imágen-esquema es una gestalt mental que evoluciona a partir de una experiencia corporal y forma las bases para la construcción de conceptos y núcleos de significado. Las representaciones pasan de representaciones perceptuales a representaciones conceptuales y simbólicas, construyéndose así los modelos de trabajo o modelos representacionales (Bowlby, 1983).

El entorno juega un papel fundamental ya que es a partir de la experiencia interpersonal con figuras significativas que se van construyendo nuestras representaciones mentales. La repetición de éstas estructuras mentales genera representaciones esquemáticas de patrones generalizados que son almacenados semánticamente dando lugar, como ha propuesto Knox (2003), a patrones de significado que se reiteran regularmente:

constituyen el núcleo de significado que emerge con total predictibilidad en las primeras semanas del desarrollo humano con una condición - el entorno durante esas primeras semanas debe ser el entorno típico de la especie cuyo rasgo esencial es un progenitor amoroso, nutriente y atento. (Knox, 2003, p. 205)

Los patrones de significado surgen de las imágenes-esquemas, ya que estas funcionan como marcos organizadores que estructuran la experiencia y los modelos representacionales que dan sentido a la misma, donde cada nueva información es redefinida en función de la memoria implícita de significados acumulados por la experiencia a la cual se vuelve, pero de la que no somos conscientes. 
Patrones de organización y niveles de análisis

Queremos enfatizar que en la organización y dinámica de un sistema arquetípico, si bien hay una prevalencia de un determinado patrón de organización, con sus estructuras y procesos que le son propios, también coexisten e interactúan otros patrones diferentes. No olvidemos que en la organización de un sistema, en tanto es una organización en red, interactúan otros sistemas, con la especificidad que le confieren sus propios patrones. En la activación de un sistema arquetípico en red participa todo el organismo acoplado estructuralmente con el medio, podríamos decir de otra manera, participa la totalidad del ser en todas sus dimensiones: biológica, psicológica y existencial, y en todos sus contextos estructurantes: familiar, educacional, socio-cultural y ecoambiental.

En cada sistema arquetípico podemos distinguir patrones de organización que pueden ser estudiados desde diferentes niveles de análisis, los cuales corresponden a la dimensión biológica, psicológica y existencial. Cada uno de estos niveles es objeto de investigación por diferentes disciplinas, especialmente por aquellas que tienen un fuerte desarrollo en el análisis de las dimensiones biológica y psicológica. Estos patrones de organización han sido estudiados parcialmente desde el campo de la neurobiología, la psicología cognitiva y la Psicología Analítica. Nuestra propuesta es contribuir a su estudio unificado desde un dominio transdisciplinario que denominamos Psiconeurociencia simbólica. En este ámbito, el estudio unificado es posible en el entendido de que las descripciones realizadas en términos de patrones o esquemas de organización, formulados inicialmente desde la neuro-inmuno-endocrinología, y la psiconeuro-inmuno-endocrinología, pueden consolidarse actualmente en el dominio de la Psiconeurociencia como un estudio transdisciplinario de los cuatro sistemas inteligentes (endocrino, inmunológico, nervioso y psíquico) que interactúan contextuadamente en la dimensión de lo humano. Por tanto, desde esta perspectiva, el estudio de todo sistema arquetípico activado va a requerir de múltiples niveles de análisis. 
En un sistema arquetípico, en tanto sistema en red, podemos reconocer, sin abandonar la visión de totalidad, diferentes niveles de análisis que nos posibilitan la descripción de patrones neurobiológicos, cognitivos, tipológicos y del significado personal. Todos estos patrones contribuyen a nuestra organización como seres humanos, y por tanto, están también comprometidos cuando enfermamos, como observamos en los pacientes con trastornos depresivos.

\section{Depresión: construyendo una nueva cartografía}

Nuestra propuesta de contribuir a una nueva cartografía en el estudio de los pacientes con trastorno depresivo mayor, parte de que el patrón de auto-organización del sistema de la personalidad se ha modificado, generando en la dimensión biológica una descentración del eje neuroendocrino (Golstein \& Reinikoff, 1971); en la dimensión psicológica una descentración del eje ego-self, (Neumann, 1970) o del eje simbólico (Byington, 1996); y en la dimensión existencial, una alteración del eje ontoaxiológico (Saiz, 1998).

En la dimensión biológica, describimos una descentración del eje neuro-inmuno-endócrino, especialmente del eje hipotálamo-hipófisisadrenal, y del eje hipotálamo-hipófisis-tiroideo, lo cual se manifiesta en una alteración de los patrones neurobiológicos a nivel molecular, celular y sistémico.

En la dimensión psicológica, describimos una descentración del eje ego-self (Neumann, 1970), o eje yo-otro-arquetipo central (Byington, 2003) caracterizado por una disfunción defensiva en la elaboración simbólica y en la función estructurante de los símbolos, lo cual se expresa en una alteración de los patrones cognitivos y del significado personal que se explicitan en las conductas inadecuadas que presenta todo paciente con trastorno depresivo.

En la dimensión existencial, describimos una descentración del eje onto-axiológico, que se manifiesta en una alteración del sistema de valores 
de la persona con depresión mayor, lo cual se expresa como una alteración de su patrón del significado existencial personal.

La enfermedad se manifiesta así como una pérdida de armonía, del equilibrio, del centro, en otras palabras, como una verdadera descentración de la existencia (Binswanger, 1973), la cual podemos re-definirla como una descentración emergente en la interacción de los tres ejes básicos de la personalidad que expresan las modificaciones de los distintos patrones que interactúan en el sistema.

Hemos diseñado un proyecto de investigación que tiene por objetivo, en primer lugar, la investigación de los diferentes patrones de organización, tipológicos, cognitivos, y neurofuncionales en pacientes con trastorno depresivo mayor (severo y moderado). En segundo lugar, la evaluación de los resultados obtenidos luego de un año de tratamiento, y finalmente, en tercer lugar, el análisis de acuerdo a los resultados obtenidos, de como los distintos patrones, neurobiológicos, cognitivos, tipológicos y simbólicos interactúan y pueden modificarse en la dinámica de un sistema organizado desde un patrón arquetípico emergente, que podemos plantear como un patrón de organización depresivo. Antes de presentar nuestro diseño de investigación, describiremos sintéticamente los diferentes patrones que serán objeto de estudio en la misma.

\section{Patrón neurobiologico}

En el contexto de la Neurociencia podemos plantearnos que el patrón de organización, al cual hacíamos referencia como patrón autopoiético, encuentra una de sus formas de expresión en los patrones neurobiológicos del cerebro. La actividad funcional del cerebro, registrada por las técnicas de neuroimagen como la tomografía por emisión de positrones (PET) y la tomografía computarizada por emisión de fotón único (SPECT) ponen de manifiesto los patrones neurobiológicos prevalentes en sus diferentes sistemas y estructuras neuronales. 
El SPECT cerebral es un estudio que nos posibilita evaluar el flujo sanguíneo de las diferentes áreas cerebrales. Proporciona información acerca del funcionamiento de éste órgano, permitiendo el diagnóstico de aquellas patologías en que la perfusión cerebral esta comprometida, como se observa en los trastornos depresivos mayores. ${ }^{3}$

Las investigaciones realizadas muestran que en casi un 100\% de los casos, el patrón neurobiológico funcional registrado en términos de neuroimágenes en los pacientes con depresión mayor, presenta una hipoperfusión en el córtex prefontal (dorso-ventral) ${ }^{4}$, así como también, una hipoperfusión temporal anterior. Estas estructuras serán estudiadas con el SPECT, como proponemos en nuestro diseño de investigación, antes y después del tratamiento realizado para la depresión, para evaluar las modificaciones funcionales operadas.

\section{Patrón cognitivo}

En el contexto de la Psicología Cognitiva, podemos plantearnos que el patrón de organización de los seres vivos, al cual hacíamos referencia como patrón autopoiético, encuentra una de sus formas de expresión en el patrón cognitivo o esquema cognitivo (Beck, 1983).

Los esquemas son patrones cognitivos bastantes estables y constituyen la base de las interpretaciones; son los que organizan la información que se recibe en

3 Esta técnica tiene dos aplicaciones actuales en la clínica: el estudio de la perfusión o flujo sanguíneo cerebral (FSC) junto a las alteraciones metabólicas y el estudio de los receptores cerebrales. El SPECT nos permite evaluar eficazmente las modificaciones funcionales de los patrones neurobiológicos, registrados en neuroimágenes, correspondientes a los trastornos afectivos en función del conocido paralelismo entre la actividad neuronal, metabolismo y flujo sanguíneo cerebral (FSC), posibilitando de esta manera un re-testeo como proponemos en nuestra investigación.

4 La hipoperfusiòn en el cortex prefrontal, muestra un compromiso precisamente en el córtex frontal dorsal (orbito frontal) y en el córtex frontal ventral. 
cogniciones, formando una red o matriz a través de la cual pasan y se resignifican los datos de nuestras experiencias. (Daset, 2002, p. 183)

Los patrones de organización cognitiva tienen su corporeización psíquica en ciertas unidades estructurales del psiquismo: las cogniciones, y en sus relaciones funcionales (o disfuncionales) entre pensamientos, creencias, atributos y afectos. En el vínculo entre patrón (esquema) y estructura (cognición), reside el proceso, que a nuestro modo de ver, puede asimilarse a lo que Beck (1983) denomina operaciones cognitivas. Ellas son procesos que operan de forma interactiva para procesar la información de acuerdo a las estructuras y proposiciones cognitivas que expresan una determinada organización que viene dada por el patrón cognitivo activado.

La activación pronunciada de esquemas disfuncionales está en el núcleo de los trastornos depresivos. Los esquemas más idiosincrásicos, disfuncionales, desplazan a los más adaptativos, orientados a la realidad, en funciones tales como el procesamiento de la información, el recuerdo y la previsión. Estos patrones se organizan en base a las creencias irracionales que llevan a conductas y emociones autocastigadoras (Ellis, 1981), o a los patrones cognitivos de la tríada de Beck, que sustentan en el depresivo su visión negativa de sí mismo, del mundo y del futuro (Beck, 1983).

\section{Patrón tipologico}

En el contexto anterior de las cogniciones, como estructuras propias del ser humano organizadas de acuerdo a un patrón, encontramos las funciones de la conciencia descritas por Jung. Estas funciones pueden ser consideradas procesos cognitivos. (Berens, 1999). Cuando describimos un patrón de organización tipológico predominante hacemos referencia a un modo específico de configurar las relaciones entre los diferentes componentes estructurales que intervienen en nuestras cogniciones. El vinculo entre el patrón (tipológico) y estructura (sensación, intuición, pensamiento, sentimiento) es mantenido por los procesos cognitivos en tanto actividades que desempeña el sistema en su funcionamiento, en su 
desarrollo y adaptación. Los procesos son dinámicos y cambiantes. No podemos observarlos directamente, pero contamos con su evidencia a nivel de la conducta. Estos procesos o funciones cognitivas interactúan de tal manera que conforman junto a la extraversión e introversión ocho patrones tipológicos que van a marcar formas cognitivas diferentes de organizar el mundo interno y externo, estando presentes en toda instancia de aprendizaje, comunicación humana o resolución de problemas.

\section{Patrón simbólico o del significado personal}

En el contexto de la Psicología Analítica el patrón de organización, al cual hacíamos referencia como patrón autopoiético encuentra una de sus formas de expresión en los patrones del significado personal ${ }^{5}$. Estos patrones son constitutivos del proceso de auto-organización que caracteriza el desarrollo de la individuación. Mientras la descripción del patrón de organización implica una cartografía de relaciones arquetipales, la estructura, en tanto corporeización psíquica del patrón, nos remite a los símbolos y sus relaciones como las estructuras-dinámicas que tejen la trama psíquica de la significación personal.

Los símbolos tienen una función estructurante en la formación y transformación de la identidad del Yo y del Otro en función del sistema arquetípico prevalente. (Byington, 1996, 2003). La organización estructural de las relaciones entre las funciones estructurantes creativas y defensivas, genera unidades de organización más complejas que fueron descriptas por Jung como complejos cargados afectivamente (Jung, 1934/1968, p. 93).

De la misma manera que el cambio continuo era una propiedad de los sistemas vivos que sugería la noción de proceso, también en la dimensión de lo psíquico consciente e inconsciente, reconocemos el proceso simbólico

5 El término patrones del significado personal es tomado de la publicación de Guidano (1994): "El sí mismo en proceso" y redefinido en el marco del proceso de individuación propuesto por Jung. 
como el propio proceso de lo psíquico. Este proceso es la actividad experiencial - o vivencial - que se ocupa de la continua elaboración simbólica o construcción del significado personal. Es un proceso por el cual los símbolos estructurantes posibilitan el desarrollo y transformación del Yo y del Otro como realidad emergente desde el Self, transformación de la personalidad y de la cultura, lo denominamos de elaboración simbólica (Byington, 1996).

La elaboración simbólica es un proceso donde el símbolo no puede ser reducido a una cosa sino que es parte de un proceso de cognición y significado que define el proceso mismo de la existencia humana. El símbolo es estructura cognitiva y proceso vivencial desde donde trabaja la elaboración simbólica para develar, para posibilitar la emergencia de un sentido en el marco de un sistema de significaciones personales, construido en la recursividad de nuestras experiencias cognitivas e imaginales y nuestra comprensión significativa de las mismas. El símbolo se constituye así en una estructura estructurante en todo el proceso de auto-organización y autorealización del sí-mismo, actividad esta que Jung denomina proceso de individuación. Si ontológicamente el modo humano de ser en el mundo consiste en buscar y crear significado, de ser posible, dentro de la dimensión intersubjetiva, nuestro desafío es poder identificar la permanencia de organizaciones del significado personal, de la misma manera que identificamos diferentes constituciones físicas en la constancia morfológica del cuerpo humano.

La finalidad de nuestra propuesta de investigación es contribuir al estudio y al análisis de los puentes psíquicos que pueden describirse, en términos de patrones de organización emergentes, desde las investigaciones en las neurociencias y las psicociencias. Esta complementariedad e integración es la que posibilita la construcción de ese dominio transdisciplinario que hemos denominado Psiconeurociencia simbólica, desde donde investigaremos los patrones de organización implicados en los trastornos depresivos. 


\section{Reflexiones finales: depresión e investigación}

A modo de conclusión, podemos decir que en el dominio de la Psiconeurociencia simbólica, el énfasis de nuestra propuesta ha transitado desde los problemas interdisciplinarios que plantea el tema inicial de la relación cerebro-mente a la construcción de una perspectiva más abarcativa y ecosistémica de cómo interactúan los diferentes patrones de organización en esa red de sistemas arquetípicos, para posibilitar la auto-organización y auto-referencialidad del ser humano en la construcción de su individuación.

La tarea de la individuación consiste en una continua ampliación de la conciencia en general, y a la vez, en la creación de una conciencia individual de sí mismo, que como ha señalado Jung y "hasta donde sabemos, el hombre es la única criatura que puede descubrir el sentido" (Jung, 1959/1975, p. 493)

En los pacientes con trastornos depresivos mayor, encontramos una verdadera descentración de la existencia (Binswanger, 1973), una descentración que caracteriza al ser enfermo en todas sus dimensiones y contextos, en todos sus componentes estructurales y relacionales, y que conlleva a la descentración del sentido de la existencia resultante de la desintegración del sistema de significaciones personales.

La descentración del sentido existencial requiere, desde el nivel psicológico, la elaboración simbólica del sufrimiento que genera, donde el mismo se torna una experiencia simbólica capaz de instaurar un nuevo y diferente sentido vital. La dificultad no está en el hecho de sufrir, sino en la manera de sufrir, en cómo el hombre se enfrenta consigo mismo (Saiz, 2002). Es la posibilidad de creación de una nueva conciencia, nacida del sufrimiento, y la vez, fuente de transformación de los sistemas de significación personal, que en definitiva, se constituyen en la transformación del sentido de la vida, que en muchos casos, es de por vida.

Finalmente, proponemos una reflexión a partir de los aportes que surjan de los resultados obtenidos en nuestra propuesta de investigación, con el propósito de contribuir al conocimiento y descripción de un patrón de 
organización depresivo, en el contexto del dominio transdisciplinario de la Psiconeurociencia simbólica.

En definitiva, nuestra iniciativa ha sido re-visionar y estudiar como los patrones arquetípicos que intervienen en la depresión, de acuerdo a los aportes e investigaciones en el campo de las psiconeurociencias, responden a la propuesta de Jung de mirar con una visión sistémica o de totalidad el fenómeno de la vida, de la psique y del cuerpo. Esperamos así estar contribuyendo a una nueva mirada de lo humano.

Saiz, M. E. \& Amézaga, P. (2005). Psychoneuroscience and archetypes building a dialog between analytical psychology and neuroscience. Psicologia USP, 16 (3), 95-117.

\begin{abstract}
The sustained development of neurosciences in the study of the brain and human conduct, together with the building of epistemological bridges between brain and human soul among psicosciences, has began to create an integration and complementation of knowledge coming from different scientific disciplines, integration which is looking forward to create a mind-brain unified theory. In the context of this creation of knowledge, the authors are now introducing a new concept named Psiconeuroscience, in order to create a transdisciplinary space of study of the relationships between mind and brain, between neuroscience and psicoscience. Starting from this point of view the authors make a re-vision of the concept of archetype proposed by Analytical Psychology in the light of the contributions made by neuroscience and cognitive psychology to describe as an example of this re-formulation, the patterns of organization that interact in depressive disorders.
\end{abstract}

Index terms: Neuroscience. Neuropsychology. Junguian psychology.

Saiz, M. E. \& Amézaga, P. (2005). Psychoneuroscience et archetypes construisant un dialogue entre la psychologie analytique et la neuroscience. Psicologia USP, 16 (3), 95-117. 


\section{Psiconeurociencia y Arquetipos}

Résumé : Le développement soutenu de la neuroscience dans l'étude du cerveau et la conduite humaine, avec le développement des ponts épistémologiques entre les psicosciences, spécialement par rapport à l'étude de l'esprit et à l'âme humaine, a commencé à produire une complémentarité et une intégration de la connaissance depuis différentes disciplines scientifiques, cherchant la formulation d'une théorie unifiée cerveau- esprit. Dans le contexte de cette génération de connaissance, est apparue la proposition des auteurs d'un espace transdisciplinaire d'étude des relations entre l'esprit et le cerveau entre des neurosciences et des psicosciences, qui s'appellent Psiconeuroscience. Dans cette perspective les auteurs proposent une révision de la notion de d'archétype formulé par la Psychologie Analytique à la lumière des apports de la neuroscience et de la psychologie cognitive, pour décrire comme exemple de cette reformulation, les patrons d'organisation qui interactuent les bouleversements dépressifs.

Mots-clés: Neuroscience. Neuropsychologie. Psychologie jungienne.

\section{Referencias}

Beck, A. (1983). Cognitive therapy of depression. New York: Raven.

Berens, L. (1999). Dynamics of personality type: Understanding and applying Jung's cognitive processes. Huntington Beach,CA: Telos.

Bateson, G. (1991). Pasos hacia una ecología de la mente. Buenos Aires: Planeta.

Bertalanffy, L. von (1975). Perspectivas en la Teoría General de Sistemas. Madrid: Alianza.

Binswanger, L. (1973). El caso de Ellen West. In R. May et al., Existencia. Madrid: Gredos.

Bowlby, J. (1983). La perdida afectiva: tristeza y depresión. Buenos Aires: Paidós.

Byington, C. (1996). Arquétipo da vida e o arquétipo da morte. Junguiana, 14, 92-115.

Byington, C. (2003). A construção amorosa do saber: o fundamento e a finalidade da Pedagogia Simbólica Junguiana. São Paulo: Religare.

Daset, L. (2002). De las cogniciones a la depresión: el camino hacia la tristeza. Prisma, 18, 178-192.

Ellis, A. (1981). Razón y emoción en psicoterapia. Bilbao, España: DDB. 
Goldstein, A., \& Reinikoff, M. (1971). Suicide in chronic hemodialysis patients from an external locus of control framework. American Journal of Psychiatry, 137, 124127.

Guidano, V. (1994). El sí-mismo en proceso. Barcelona: Paidós.

Hogenson, G., Stevens, A., \& Ramos, D. (2003). Psychology and biology. In Proceedings of the Fifteenth International Congress for Analytical Psychology, Einsiedeln, Switzerland: Daimon Verlag.

Jung, C. G. (1968). A review of the complex theory. In Collected Works (Vol. 8). New Jersey: Princeton University Press. (Trabalho original publicado en 1934)

Jung, C. G. (1968). Psychological factors determining human behaviour In Collected Works (Vol. 8). New Jersey: Princeton University Press. (Trabalho original publicado en 1937)

Jung, C. G. (1969). The three persons in the light of psychology. In Collected Works (Vol. 11). New Jersey: Princeton University Press. (Trabalho original publicado en 1942)

Jung, C. G. (1970). The conjunction. In Collected Works (Vol. 14). New Jersey: Princeton University Press. (Trabalho original publicado en 1944)

Jung, C. G. (1968). On the nature of the psyche. In Collected Works (Vol. 8). New Jersey: Princeton University Press. (Trabalho original publicado en 1954)

Jung, C. G. (1968). The Archetypes and the Collective Unconscious. In Collected Works (Vol. 9). New Jersey: Princeton University Press. (Trabalho original publicado en 1959)

Jung, C. G. (1975). Carta a E. Neumann del 10 de Marzo de 1959. In Letters. New Jersey: Princeton University Press. (Trabalho original original publicado en 1959)

Kandel, E., Schwartz, J., \& Jessel T. (2001). Neurociencia y conducta. Madrid: Prentice Hall.

Knox, J. (2003). Archetype, attachment, analysis. New York: Brunner-Routldege.

Mandler, J. (1992). How to build a baby II: conceptual primitives. Psychological Reviex, 99(4).

Maturana, H. (1996). Desde la biología a la psicología. Santiago de Chile: Editorial Universitaria.

Maturana, H., \& Varela, F. (1987). The tree of knowledge. Boston: Shambhala.

Maturana, H., \& Varela, F. (1980). Autopoiesis and cognition: the organization of the living. Boston: Reidel. 


\section{Psiconeurociencia y Arquetipos}

Neumann, E. (1954). The origins and history of consciousness. New York: Routledge \& Kegan Paul.

Neumann, E. (1970). The child. New York: Putnam's Sons.

Saiz, M. E. (1998). Tecnología, depresión y transformación. Aportes epistemológicos en clínica. Junguiana, 16, 7-17.

Saiz, M. E. (1999). Niveles de integración en neurociencia cognitiva. Trabajo presentado en 1ras. Jornadas Latinoamericanas de Neurociencia Cognitiva, Buenos Aires.

Saiz, M. E. (2000). El inconsciente y la Neurociencia: o un diálogo de integración entre Psicología Junguiana y Neurociencia. Trabajo presentado en el XVI Congreso Argentino de Psiquiatría, Mar del Plata.

Saiz, M. E. (2002). Depresión: ¿un camino de transformación?, Prisma, 18, 118-147.

Saiz, M. E. (2003). Latin America: cartography of frontiers and symbolic interstices. Proceedings of The Fifteenth International Congress for Analytical Psychology. Einsiedeln, Switzerland: Daimon Verlag.

Stevens, A. (2003). An updated natural history of the self. Toronto: Inner City Books.

Stevens, A., Hogenson, G., \& Ramos, D. (2003). Psychology and biology. In Proceedings of the Fifteenth International Congress for Analytical Psychology. Einsiedeln, Switzerland: Daimon Verlag.

Varela, F. (1988). Connaître: les sciences cognitives. Paris: Seuil.

Varela, F., \& Hayward, J. (1997). Un puente para dos miradas. Santiago: Dolmen.

Saiz, M. E. (2001)

Saiz, M. E. (2004)

Recebido em: 8.12.2004

Revisto em: 3.06.2005

Aceito em: 20.08.2005 